\title{
Diversity and Sources of Airborne Eukaryotic Communities (AEC) in the Global Dust Belt over the Red Sea
}

\author{
Nojood A. Aalismail ${ }^{1}\left[\right.$ · Rubén Díaz-Rúa ${ }^{1} \cdot$ Nathan Geraldi $^{1} \cdot$ Michael Cusack $^{1} \cdot$ Carlos M. Duarte $^{1}$
}

Received: 8 April 2021 / Revised: 14 April 2021 / Accepted: 15 April 2021 / Published online: 8 May 2021

(c) The Author(s) 2021

\begin{abstract}
Airborne eukaryotic communities (AEC), rank among the least studied aerobiological components, despite their adverse impacts on human health and the environment. Here, we describe the AECs in the global dust belt, the area between the west coast of North Africa and Central Asia, which supports the highest dust fluxes on the planet. We sampled atmospheric dust over 14 months (fall 2015-fall 2016) from onshore and offshore locations of the Red Sea, the only waterbody that entirely encompassed in the global dust belt. We also sampled surface water samples to determine the potential transfer of taxa across the air-sea interface. To target the eukaryotes, we performed Miseq sequencing of atmospheric dust and surface water samples. Analysis of amplicon sequencing indicates a total pool of 18,816 sequence variants (SVs). Among 33 unique eukaryotic phyla in the AEC over the Red Sea, the most dominant taxa were Streptophyta, Apicomplexa, and Ascomycota. Aerosol eukaryotes originated from various sources and formed more diverse communities than eukaryotic communities of the Red Sea surface water. AECs were dominated by phylotypes released from plant material and soils, and including taxa reported to be harmful to human health. The AEC composition was significantly influenced by sampling locations and seasonal conditions but not by the origin of the air masses nor dust loads. This work is original and uses state-of-the-art methods and very powerful NGS- bioinformatics and statistical approaches. The selected study site has high interest and it has been well chosen because of the unique combination of high loads of dust deposition, being the only fully contained seawater body in the area acting as a sink for the atmospheric dust, and the lack of riverine inputs and watershed effects empathizing the role of atmospheric inputs in the ecology of the system.
\end{abstract}

Keywords Atmosphere $\cdot$ Eukaryotes $\cdot$ Bioaerosols $\cdot$ Red Sea $\cdot$ Global dust belt $\cdot$ Airborne dust microbiome

\section{Introduction}

The atmosphere plays a fundamental role in transporting microorganisms across ecosystems and connecting the planet's microbial habitats on the Earth's surface (Fröhlich-Nowoisky et al. 2016; Mayol et al. 2017). Bioaerosols communities include many diverse and important microbial organisms such as plant cell debris, pollen, fungi, microalgae, cyanobacteria, bacteria, and viruses, many of which may affect the plant, animal, and human health (Yamaguchi et al. 2012; Wiśniewska et al. 2019). Airborne eukaryotic communities are among the least studied fields

Nojood A. Aalismail

Nojood.aalismail@kaust.edu.sa

1 Red Sea Research Centre and Computational Bioscience Research Center, King Abdullah University of Science and Technology, Thuwal 23955-6900, Saudi Arabia in aerobiology. Characterizing the presence of eukaryotic eDNA (including microeukaryotes and eukaryotic debris and fragments) in air masses is fundamental to identify sources of micro- and macro-eukaryote-derived allergens and harmful agents. Eukaryotic eDNA can help understand air quality, as well as an environmental and metrological process affecting airborne communities (Woo et al. 2013; Clare et al. 2021). Airborne Eukaryotic Communities (AEC) include large biological particles $(>2 \mu \mathrm{m})$, which may be transported across thousands of kilometers over the ocean in a concentration ranged between $1 \times 10^{2}$ and $1.8 \times 10^{4}$ cells $\mathrm{m}^{-3}$ air (median $3.2 \times 10^{3} \mathrm{~m}^{-3}$ air) before deposition (Mayol et al. 2017). AEC appear to be impacted by environmental factors to a greater extent than airborne bacteria do (Tanaka et al. 2019). Therefore, adaptation to the conditions of the harsh environment characteristic of the airborne lifestyle (Aalismail et al. 2019) might allow AEC to remain viable during airborne across long distances. 
Several unicellular eukaryotes have been found to be associated with atmospheric dust particles (Griffin 2007). The atmosphere is particularly enriched in dust particles in the "global dust belt", a massive dusty region that extends from the west coast of North Africa, through the Middle East, into Central Asia (Prospero et al. 2002). In this region, the only fully contained seawater body is the Red Sea, therefore, can act as a sink for about $6 \mathrm{Mt}$ of annual atmospheric dust (Prakash et al. 2015). In general, airmass and atmospheric events have been known as carriers of toxins, bioaerosols, and pollutants which reported to cause decline or shift in some marine populations after the atmospheric depositions (Vila-Costa et al. 2013; TovarSãnchez et al. 2014; Rahav et al. 2016; Bianco and Passananti 2020). Hence, transported dust particles can be the sources of microbial eukaryotic communities shifts in the Red Sea, which requires a characterization of the airborne eukaryotic communities over the Red Sea.

Characterizing AEC is particularly important in the context of rising atmospheric dust loads as a consequence of global warming and increased desertification with global (IPCC 2013). While the Red Sea is located in a desert region and receive inputs of micro-eukaryotes from heavy dust loads, it may also act as a source of micro-eukaryotes to the atmosphere (Genitsaris et al. 2014). Since there are no riverine inputs into the Red Sea, atmospheric inputs represent a particularly important conduit for inputs of biological particles and trace metals, which might enhance the biological productivity as a consequence of nutrients richness. While a number of recent studies examine the airborne prokaryotic community (APC) over water bodies (Cho and Hwang 2011; Genitsaris et al. 2017; Michaud et al. 2018; Yahya et al. 2019; Aalismail et al. 2020), the AEC in the marine ecosystem has received limited attention.

We studied the abundance and diversity of the AEC over the Red Sea and compare this to the eukaryotic community in Red Sea surface waters. To do so, we characterize communities in dust samples collected every 1-7 days over a period of 1 year from onshore and offshore sites in the Eastern Red Sea, as well as surface water samples for comparative purposes.

We used amplicon sequencing of $18 \mathrm{~S}$ rRNA to characterized likely sources and community structure of the AEC along the coast and above the Red Sea and its association with the pelagic planktonic eukaryotic comminutes. To estimate the sources of airborne dust, we computed the air-mass backward trajectories using HYSPLIT (Stein et al. 2015). In this study, we tested four hypotheses: (1) the structure of AEC is similar to the Red Sea surface water eukaryotic communities, (2) the AEC will include pathogens to human, plants, and animals, (3) the diversity of AEC will be influenced by the long-range atmospheric transport history, and (4) the AEC structure will vary according to seasonal conditions.

\section{Materials and Methods}

\subsection{Study Area and Samples Collection}

Airborne dust particles were sampled using an air pump at a flow rate of $20 \mathrm{~m}^{3} \mathrm{~h}^{-1}$ over periods of $24 \mathrm{~h}$ to 1 week using automatic sequential high-volume samplers (MCV-CAV) until the filter was clogged, which involved sampling periods ranging from $24 \mathrm{~h}$, during dust storms, to 1 week, when dust loads were lowest. The air suspended particles were collected on quartz fiber filters (WhatmanTM 1810-150 Acid Treated TCLP Filter for EPA Method 1311 with Low Metals, diameter: $15 \mathrm{~cm}$, pore size: $0.6-0.8 \mu \mathrm{m})$. Onboard the research vessel, the atmospheric dust collector was placed on the top deck at a height of $\sim 7.5 \mathrm{~m}$ over the sea level. It was equipped with a weather vane, which would switch off the pump and thus terminate sampling promptly at whatever point the sampler was downwind of the ship's exhaust. The dust particle concentration was measured by weighing the filters before and after sampling and expressed as $\mu \mathrm{g} \mathrm{m}^{-3}$. Atmospheric dust samples were collected at two sites, the onshore (KAUST samples) and offshore (Thuwal samples) regions of the Red Sea (Fig. S1) from September 2015 to November 2016 (Table S1). The onshore sampling site is an international university with many constructions and industrial activities.

At the coast of KAUST, surface Red Sea water was collected in $20 \mathrm{~L}$ plastic bottles and filtered through $0.22 \mu \mathrm{m}$ membrane filters (Millipore) every two weeks from June 2016 to November 2016. Individual filters were stored in $15 \mathrm{~mL}$ tubes and immediately frozen at $-20^{\circ} \mathrm{C}$.

Different filters were used for air and water samples because the filters with a pore size $(0.6-0.8 \mu \mathrm{m})$ are large enough to collect airborne dust particles, where the cells are attached $(\sim>2.1 \mu \mathrm{m})(\mathrm{Li}$ et al. 2011$)$, as the aim was to collect dust-associated cells. However, pelagic planktonic eukaryotic comminutes contain both free-living and particle-associated cells, thus sample collection requiring smaller pore size filters $(0.22 \mu \mathrm{m})$. Surface water samples were collected only for community structure comparisons, thus the seasonal sampling for pelagic planktonic eukaryotic comminutes was not required. Moreover, after sequencing and during the analysis, a subsampling step was obtained for the normalization. Therefore, different sample sizes may did not consider as a limitation for this study. 


\subsection{DNA Extraction}

DNA was extracted from 129 dust filters samples and ten water filters samples using phenol-chloroform extraction protocol. To keep samples for further studies, we used a quarter of each sample filter for DNA extraction. A new clean filter was used as an extraction control. Filters were sheared into pieces to aid the performance of lysis buffer [0.5 M EDTA, $1 \mathrm{M}$ Tris- $\mathrm{HCl}(\mathrm{pH} 8)$ and $\mathrm{NaCl}$. In a $15 \mathrm{~mL}$ centrifuge tube, we added to the filter pieces $5 \mathrm{~mL}$ of the lysis buffer, $1 \mathrm{mg} / \mathrm{mL}$ lysozyme (Sigma-Aldrich, St. Louis, MO, USA), ca. $100 \mathrm{mg}$ of $0.1 \mathrm{~mm}$ glass beads (BioSpec Products, Bartlesville, OK, USA), and ca. $100 \mathrm{mg}$ of $0.1 \mathrm{~mm}$ zirconia beads (BioSpec Products, Bartlesville, OK, USA) for better DNA yield (Bürgmann et al. 2001). After mixing by shaking machine for $30 \mathrm{~min}$, tubes were incubated at $37{ }^{\circ} \mathrm{C}$ for 30 min with inverting halfway through the incubation. After that, we added $205 \mu \mathrm{L}$ of $20 \%$ SDS and $10 \mu \mathrm{L}$ of proteinase K (QIAGEN, Valencia, CA, USA Cat. No. 19133) to each tube and vortexed them for $10 \mathrm{~s}$ before incubating at $55^{\circ} \mathrm{C}$ for $2 \mathrm{~h}$. During the incubation time, tubes were inverted every $30 \mathrm{~min}$ to increase the extraction yield. Five $\mathrm{ml}$ of phenol-chloroform-isoamyl alcohol (Sigma-Aldrich, St. Louis, MO, USA) was then added and the sample was centrifugation for $10 \mathrm{~min}$ at maximum speed. Carefully and without disrupting the white interference layer, the supernatant was transferred to a new microcentrifuge tube. Then, phenol was removed from the mixture by adding $5 \mathrm{ml}$ of chloroform-isoamyl alcohol (AppliChem, GmbH, Darmstadt, DE) to each tube, followed by microcentrifugation for $5 \mathrm{~min}$. After spinning, we transferred the supernatants to 10,000 MW cutoff Amicon Ultra centrifugal filters (Millipore, Burlington, MA, USA) and twirled samples for $15 \mathrm{~min}$ on a swinging rotor. The lower tube filtrates were thrown away and $5 \mathrm{ml}$ of $10 \mathrm{mM}$ Tris- $\mathrm{HCl}$ was added to each tube and centrifuged until the volume reduced to $<250 \mu \mathrm{L}$. Once more, we removed filtrates and $10 \mathrm{mM}$ Tris- $\mathrm{HCl}$ was added to each tube to reach $250 \mu \mathrm{L}$ after mixing. The upper layer volume, which contained the extracted DNA was moved to size $2 \mathrm{~mL}$ Eppendorf tubes.

Qubit dsDNA HS (High Sensitive) Assay Kit (Thermo Scientific, Invitrogen, Carlsbad, CA, USA) and Promega ${ }^{\circledR}$ GloMax-Multi Detection System (Promega Corporation, Madison, WI) were used for DNA quantification.

\subsection{S rRNA Gene Amplicon Library Preparation and Sequencing}

The V4 variable region of $18 \mathrm{~S}$ rRNA was amplified for Illumina sequencing using the universal primers fused with Illumina adapter overhang nucleotide sequences.

The primer pair $(0.3 \mu \mathrm{L}, 10 \mu \mathrm{M})$ specific sequences were the forward primer (5'TCGTCGGCAGCGTCAGATGTG
TATAAGAGACAGCCAGCASCYGCGGTAATTCC3') and the reverse primer ( $5^{\prime}$-GTCTCGTGGGCTCGGAGA TGTGTATAAGAGACAGACTTTCGTTCTTGATYRA-3') (Stoeck et al. 2010) targets a 350-425 bp region.

Library preparation and amplification were performed using Qiagen Taq PCR Master Mix Kit in $20 \mu \mathrm{L}$ reaction volume. A strategy of two-step PCR amplification was followed, the conditions were $95{ }^{\circ} \mathrm{C}$ for $15 \mathrm{~min}, 15$ cycles of $98{ }^{\circ} \mathrm{C}$ for $10 \mathrm{~s}, 53{ }^{\circ} \mathrm{C}$ for $30 \mathrm{~s}$, and $72{ }^{\circ} \mathrm{C}$ for $30 \mathrm{~s}, 20$ cycles of $98^{\circ} \mathrm{C}$ for $30 \mathrm{~s}, 48^{\circ} \mathrm{C}$ for $30 \mathrm{~s}$, and $72{ }^{\circ} \mathrm{C}$ for $30 \mathrm{~s}$, with a final extension at $72{ }^{\circ} \mathrm{C}$ for $10 \mathrm{~min}$. A PCR control with no template DNA was included. PCR products were visualized on a $1 \%$ agarose gel. Amplicon libraries were purified according to Illumina guide (http://www.illumina. com/content/dam/illumina-support/documents/documentat ion/chemistry_documentation/16s/16s-metagenomic-libra ry-prep-guide-15044223-b.pdf) using AMPure XP beads (LABPLAN; Naas, Ireland).

Libraries purity and quantification were checked using gel electrophoresis and Qubit fluorometer. According to their quantification measurements, the targeted amplicon libraries were mixed in equal concentrations into two pools and quantified using Applied Biosystems Power SYBR Green PCR Master Mix and Agilent DNA 1000 Kit (Agilent Technologies, CA, USA). Size and purity assessments were done using Agilent 2100 Bioanalyzer (Agilent Technologies, CA, USA). Six pM of the denatured library pools were spiked with 25\% of PhiX following Illumina library protocol. The pools were sequenced into two different Illumina MiSeq lanes at the Bioscience Core Lab facilities at KAUST using $2 \times 300$ bp MiSeq reagent kit v3 (Illumina Inc., CA, USA).

\subsection{Bioinformatics Analysis of Amplicon Library Sequences}

For sequence analysis, the DADA2 pipeline was used, which has been shown to produce a high resolution of microbial populations (Callahan et al. 2016). It performs the processing steps of trimming, sequencing error corrections, filtering of phiX reads, chimeric removing, and quality control. The airborne eukaryotic communities (AEC) was described using unique sequence variants (SVs), where the sequences present as taxons identifier. Prior to quality filtering, primers were first removed from the sequence using CUTADAPT (Martin 2011) with an allowance of one error per $10 \mathrm{bp}$ in the primer sequence. In brief, DADA2 package (Callahan et al. 2016) in R version 3.5.1 (http://www.R-project.org/) was used to run the read analysis pipeline. Within the workflow (available at: https://github.com/ngeraldi/dada2-andinsect-pipeline), forward and reverse reads were trimmed to 115 and $95 \mathrm{bp}$ based on visual inspection of the error rates using the fastqPairedFilter function with two expected errors per read. The reads were then de-replicated (derepfastq 


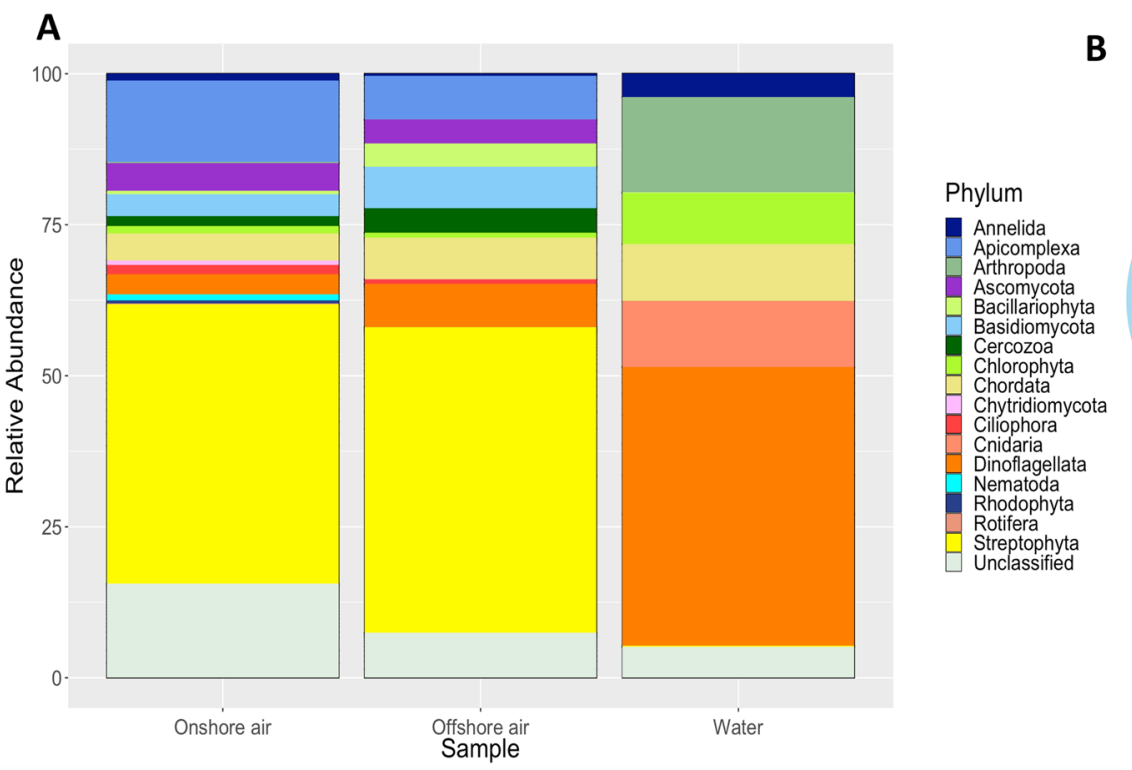

B

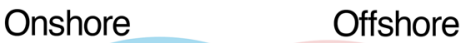

11568

348

5224

14

602 1

3183

Water

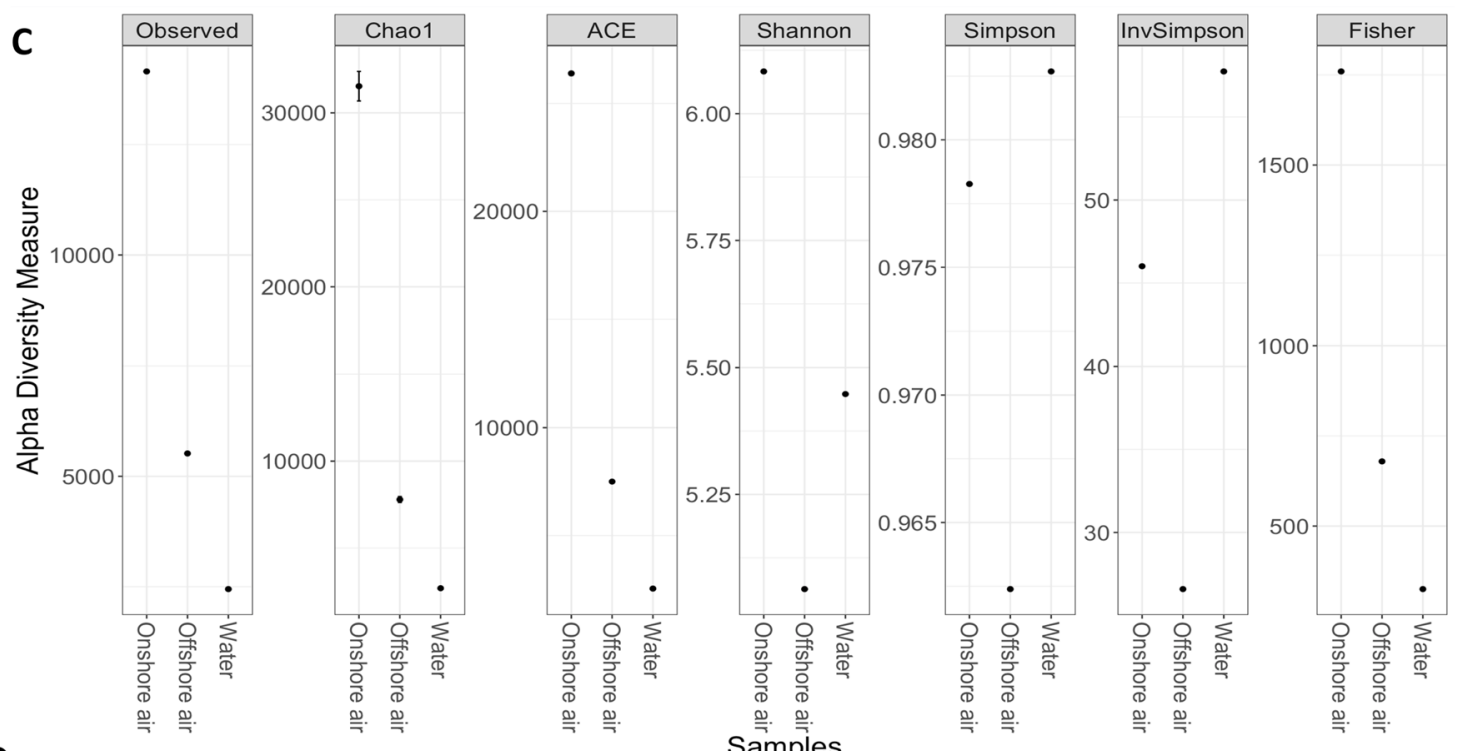

D

Samples
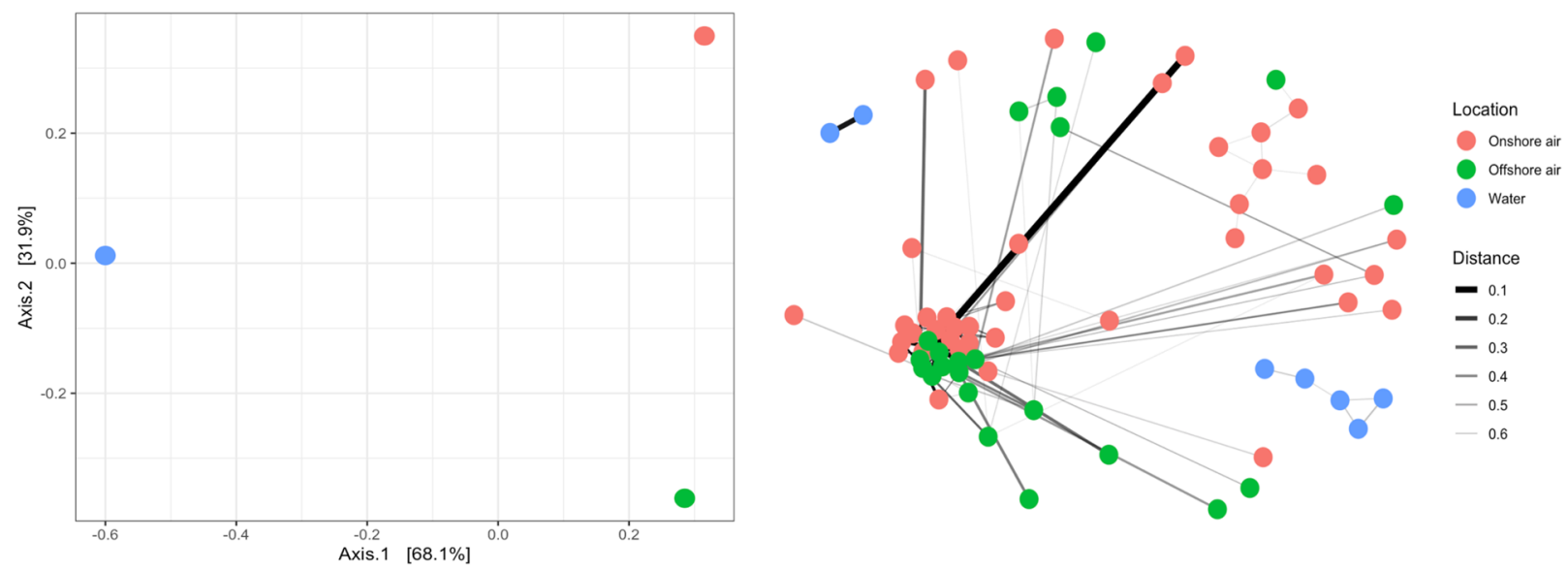
4Fig. 1 Comparison of eukaryotic populations at phylum level in three sampling locations in the Red Sea region (onshore air, offshore air, surface water). a Taxonomic composition of eukaryotic reads at the phylum level. b Three-way Venn diagram of unique and common eukaryotic phyla by sampling locations: onshore air, offshore air and surface water. C) Alpha diversity measurements of eukaryotic communities in the three sampling locations. Each panel represents one alpha diversity measure as follow: observed=total number of SVs observed; Chao1 and ACE=richness estimators (estimate the total number of SVs present in a community); Shannon, Simpson and InvSimpson=microbial indexes of diversity; Fisher=parametric index of diversity that models taxa as logseries distribution. d Beta diversity as Principal coordinates analysis (PCoA) derived from Bray-Curtis distances among samples of the three populations. The closer the samples in the graph, the higher their similarity. Each data point represents sample type, and different colors represent different sampling locations. In the same panel, a network that represents distance relationships between phyla among sampling locations based on similarity of co-occurrence relationships inferred from bray distance matrix. Thicker lines representing stronger correlations. Each data point represents an individual sample, and different colors represent different sampling location

function), and the SVs were determined using the dada function based on the reads from all samples. The perfectly matched paired reads were merged (mergePairs function), and chimera reads were removed using the removeBimeraDenovo function. To assign taxonomic classification to each SV at successively broader taxonomic levels, we used the RDP classifier that implements a naïve Bayesian classifier method (Lan et al. 2012). The assignTaxonomy function was used to assign taxonomy with the default values, except for minboot which was set at a more conservative value of 70 instead of the default of 50. A reference library was created from the SILVA database (version 132 SSU $\mathrm{Nr} 99$ ), and sequences were filtered based on in silico amplification using virtualPCR function from the insect package (Wilkinson et al. 2018) (https://github.com/ngeraldi/Train ing_datasets).

\subsection{Backward Trajectory Calculation}

Backward trajectories of individual air samples were calculated using the Hybrid Single Particle Lagrangian Integrated Trajectory (HYSPLIT) model (https://www.ready. noaa.gov/HYSPLIT.php) developed by the National Oceanic and Atmospheric Administration (NOAA) (Stein et al. 2015) at the two sampling sites in the Red Sea region (offshore and onshore). A total of 129 air mass backward trajectories reaching the middle of the global dust belt were identified at three different ending altitudes of $200 \mathrm{~m}, 300 \mathrm{~m}$, and $800 \mathrm{~m}$. The meteorological data obtained from archived data through the Real-time Environmental Applications and Display System and archived in the Global Data Analysis System (GDAS1) sampled backward up to $120 \mathrm{~h}$ (might consider as a long rang transport) using metrological data of the archived analysis.

\subsection{Statistical Analyses}

Differences between environmental variables and factors were tested using analysis of variance (Kotz et al. 2004) and $t$ test. A $p$ value of 0.05 was used to determine significance unless noted otherwise. Alpha-diversity calculations and subsequent diversity analyses were performed in $\mathrm{R}$ version 1.1.463. The analysis of structural differences between eukaryotic communities ( $\beta$-diversity) was performed using Bray-Curtis metrics. Statistical analyses and graphs were produced with JMP 14 (SAS Institute Inc. Cary, North Carolina, USA, and R software, primarily using the microbiome package phyloseq, the statistical package vegan, and the graph package ggplot2 (http://www.R-project.org/) (Wickham 2016). The numbers of SV by sampling locations were visualized using a three-way Venn diagram plot constructed using the online resource of Bioinformatics and Evolutionary Genomics (http://bioinformatics.psb.ugent.be/webtools/ Venn/).

\section{Results and Discussion}

We identified a total pool of 18,816 sequence variants (SVs) among the total $8,235,928$ reads encompassed by the data set, with an average of 59,251 reads per sample. SVs distributed among 33 unique eukaryotic phyla throughout the study, where Streptophyta dominated the communities, accounting, on average, for $25.35 \%$ of the SVs found throughout the study. Sequence variants richness in individual samples ranged from 2 to 2,265 , with an average $( \pm S E)$ of $572 \pm 43.46 \mathrm{SVs}$ per sample based on the Chao1 index at the phylum level. A total of $5562 \mathrm{SVs}$ were identified more than 2 times among the total 4,161,129 reads were identified in the onshore air samples. In the offshore air samples, 2444 SVs with $\geq 2$ counts among 2,843,534 total read counts. However, the Red Sea surface water contains 1831 SVs with 2 or more counts among the total 1,095,969 reads.

Reads that were retrieved from airborne dust samples were comprised mainly by Streptophyta (29.26\% represented mainly by Rosids and Liliopsida), Apicomplexa (12.93\% represented only by Conoidasida), Ascomycota (6.20\% represented mainly by Sordariomycetes and Saccharomycetes), Basidiomycota ( $6.14 \%$ affiliated mainly by Malasseziomycetes and Tremellomycetes), Chordata (4.23\% represented mostly by Mammalia (Cetacea) and Aves), Annelida (1.85\% dominated by Polychaeta), Chlorophyta (1.23\% represented mainly by Chlorophyceae), and Chytridiomycota (1.54\% represented mainly by Chytridiomycetes). 
A
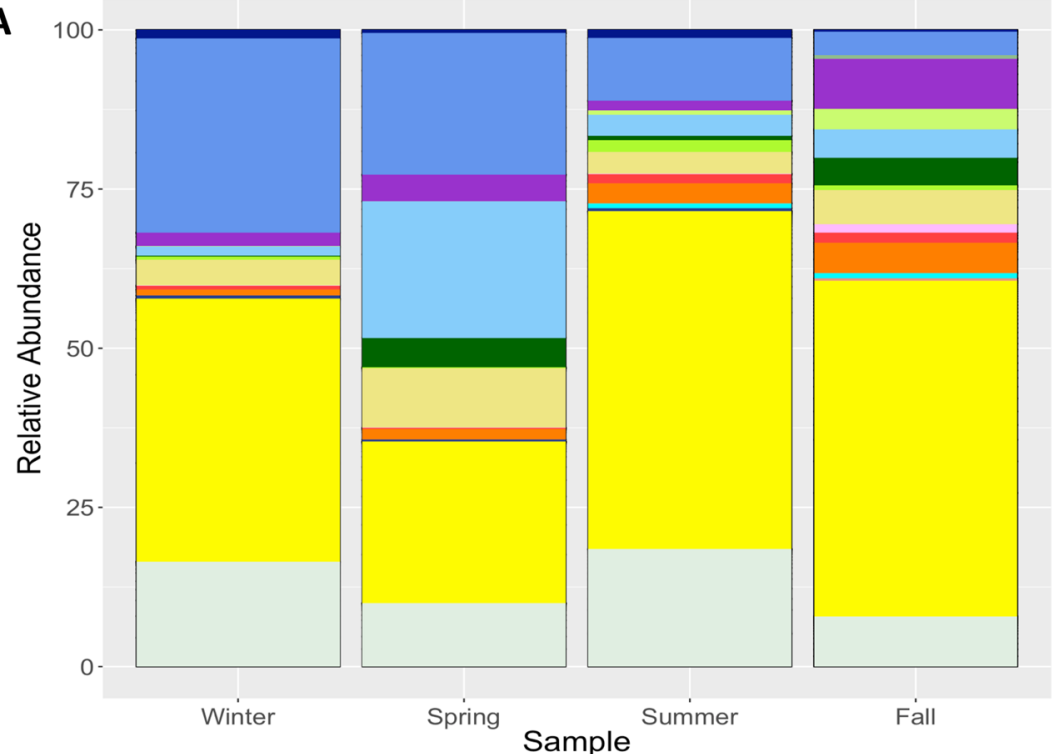

Phylum

- Annelida

Arthropoda

Ascomycota

Bacillariophyta

Basidiomycota

Cercozoa

Chlorophyta

Chordata

Chytridiomycota

Cinophora

Dinoflagellat

Nematoda

Rhodophyta

Rotifera

Streptophyt

phyta

C
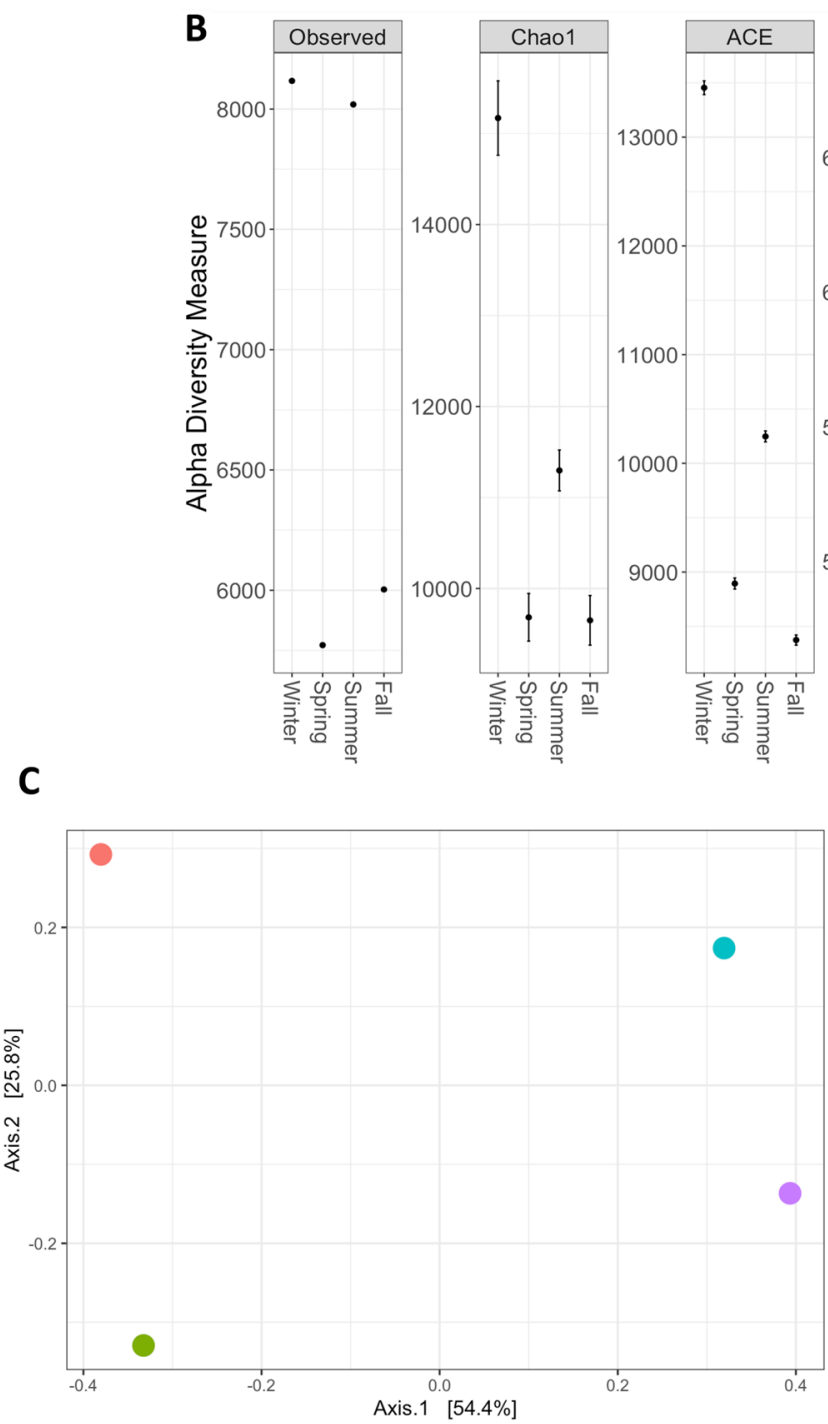

Shannon

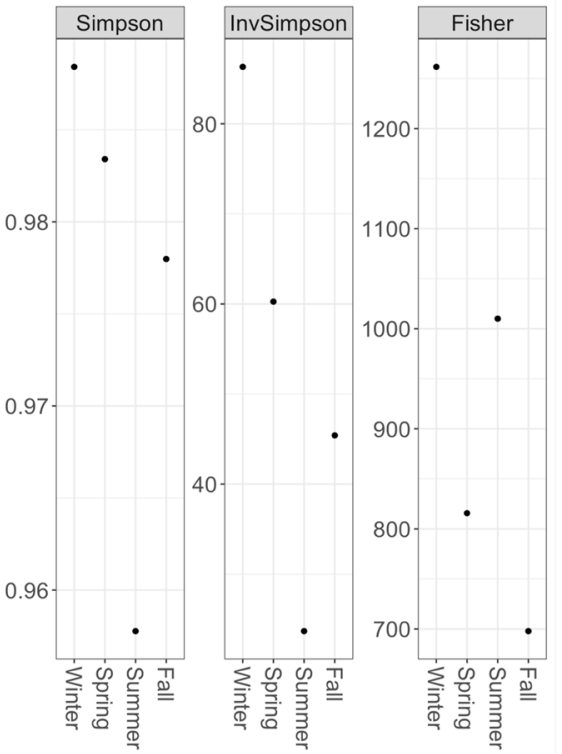

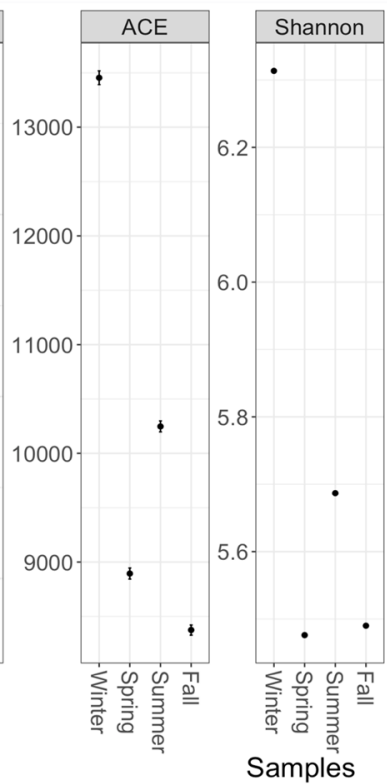

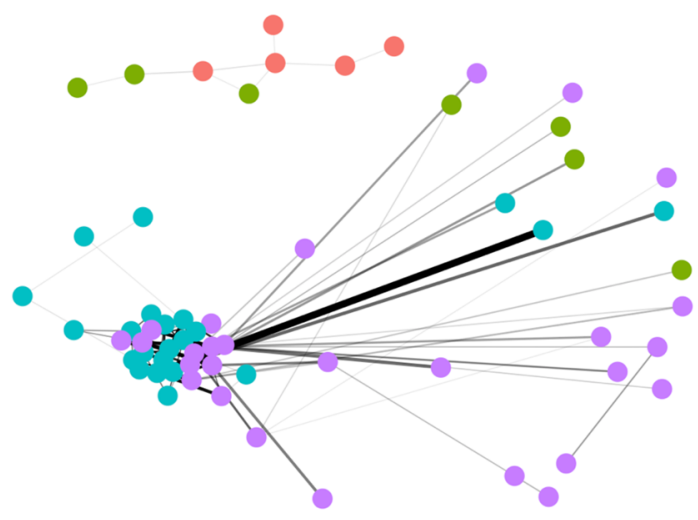

Season

Winter

spring

summer

Fall

Distance

- 0.1

$-0.2$

- 0.3

$-0.4$

- 0.5 
4Fig. 2 Comparison of eukaryotic populations at phylum level in four seasons in the Red Sea region. a Taxonomic composition of eukaryotic reads at the phylum level. b Alpha diversity measurements of eukaryotic communities per sampling seasons. Each panel represents one alpha diversity measure as follow: observed $=$ total number of SVs observed; Chaol and $\mathrm{ACE}=$ richness estimators (estimate the total number of SVs present in a community); Shannon, Simpson and InvSimpson= microbial indexes of diversity; Fisher $=$ parametric index of diversity that models taxa as logseries distribution. c Beta diversity as Principal coordinates analysis (PCoA) derived from Bray-Curtis distances among samples of the four populations. The closer the samples in the graph, the higher their similarity. Each data point represents sample type, and different colors represent different season. In the same panel, a network that represents distance relationships between phyla among seasons based on similarity of cooccurrence relationships inferred from bray distance matrix. Thicker lines representing stronger correlations. Each data point represents an individual sample, and different colors represent different season

From offshore air, reads of $18 \mathrm{~S}$ rRNA genes mostly belonged to the following phyla: Streptophyta $(39.64 \%$ represented mainly by Liliopsida), Apicomplexa (10.15\% represented only by Conoidasida), Dinoflagellates $(6.90 \%$ represented by Dinophyceae), Basidiomycota (6.44\% represented mainly by Malasseziomycetes and Tremellomycetes), Chordata (4.94\% represented mostly by Mammalia (Primates and Cetacea) and Aves), Ascomycota (4.16\% represented mainly by Sordariomycetes and Saccharomycetes), Chlorophyta (0.97\% represented mainly by Chlorophyceae), Annelida (0.95\%\% dominated by Polychaeta), and Chytridiomycota ( $0.13 \%$ represented mainly by Chytridiomycetes).

Sequences identified from onshore air samples predominantly belong to the following phyla: Streptophyta (22.04\% represented mainly by Liliopsida), Apicomplexa (14.87\% represented only by Conoidasida), Ascomycota (7.61\% represented mainly by Sordariomycetes and Saccharomycetes), Basidiomycota (5.94\% represented mainly by Malasseziomycetes and Tremellomycetes), Chordata (3.74\% represented mostly by Mammalia and Aves), Dinoflagellates (2.70\% represented by Dinophyceae), Annelida (2.48\% dominated by Polychaeta), Chytridiomycota (2.39\% represented mainly by Chytridiomycetes), and Chlorophyta ( $1.41 \%$ represented mainly by Chlorophyceae).

Reads of $18 \mathrm{~S}$ rRNA gene region retrieved from surface waters (one $\mathrm{m}$ depth) were associated to the following phyla: Dinoflagellates (50.95\% represented by Dinophyceae), Arthropoda (10.16\% mainly belong to Hexanauplia), Chlorophyta (6.65\% affiliated mostly by Mamiellophyceae and Chloropicophyceae), Chordata (2.79\% represented only by Appendicularia), and Cnidaria (2.09\% affiliated by Hydrozoa) (Fig. 1a, S2A).

The number of SVs shared by the three sampling domains (onshore air, offshore air, and surface water) was surprisingly small, only 14 SVs, whereas 348 SVs were shared between onshore air and offshore air (Fig. 1b). Surprisingly, 11,568 SVs were unique to onshore air samples, while 5,224 and 3,183 SVs were unique to offshore air and surface water samples, respectively.

Significant differences (ANOVA, $p<0.001$ ) of AEC SVs were observed among onshore air, offshore air, and surface water communities (Fig. S3A) based on Non-metric multidimensional scaling (NMDS) and principal coordinates analysis (PCoA) (Fig. 1d). The community structure of airborne eukaryotes was also different between onshore and offshore air based on PCoA and NMDS ( $p<0.002)$. Shannon diversity of AEC SVs differed significantly among sampling locations (ANOVA, $p=0.017$ ), which were higher in the airborne samples collected at offshore and onshore regions than in Red Sea surface seawater samples (Table S2, Fig. 1c). The average alpha diversity explained $8 \%$ of the variance in community structure (ANOVA, $p=0.001$ ).

The contribution of different taxa to AECs communities sampled along 14 months showed slight variations in the relative abundances among the four seasons. The most detected eukaryotic phyla in winter were Streptophyta (22.53\%), Apicomplexa (20.86\%), Basidiomycota (4.07\%), Chlorophyta $(2.76 \%)$, Chordata $(2.42 \%)$, Ascomycota (1.85\%), and Annelida (1.61\%). In addition, the main classes driving those phyla were Conoidasida, Liliopsida, Spirotrichea, Colpodea, Chlorophyceae, Tremellomycetes, Dinophyceae, Mammalia (Cetacea), Polychaeta, Saccharomycetes, and Florideophyceae.

The spring airborne dust samples harbored high numbers of Streptophyta (19.23\%), Apicomplexa (17.25\%), Basidiomycota (13.07\%), Chordata (6.50\%), Ascomycota (5.66\%), Arthropoda (1.47\%), and Annelida (1.21\%) represented by Conoidasida, Liliopsida, Spirotrichea, Colpodea, Chlorophyceae, Tremellomycetes, Dinophyceae, and Mammalia (Cetacea).

During the summer sampling period, the AEC was dominated by Streptophyta (48.87\%), Annelida (3.28\%), Ascomycota $(2.07 \%)$, and Chordata (1.76\%), Apicomplexa (1.21\%) mainly belong to Conoidasida, Malasseziomycetes, Mammalia, Sordariomycetes, Liliopsida, Spirotrichea, Dinophyceae, Colpodea, Tremellomycetes, Saccharomycetes, and Polychaeta (Fig. 2a, S2B).

There was significant clustering (ANOVA, $p<0.001$ ) differences among AEC SVS among seasons based on NMDS and PCoA (Fig. 2c, S3B) of Bray-Curtis distances among samples. The average alpha diversity of the AECs has significantly differed among seasons, which explained $8 \%$ of the variance in community structure (ANOVA, $p=0.001$ ) (Fig. 2b, Table S2, ANOVA, $p<0.001$ ). The richest and most diverse samples were those sampled in Spring 2016, with diversity being lowest in Fall 2016 (Fig. S4).

Most of the dust samples (69\%) originated from air masses from the northwest, the dominant wind direction in the Red Sea (Bower and Farrar 2015; Eladawy et al. 2017). The contribution of different phyla to AECs suspended in 

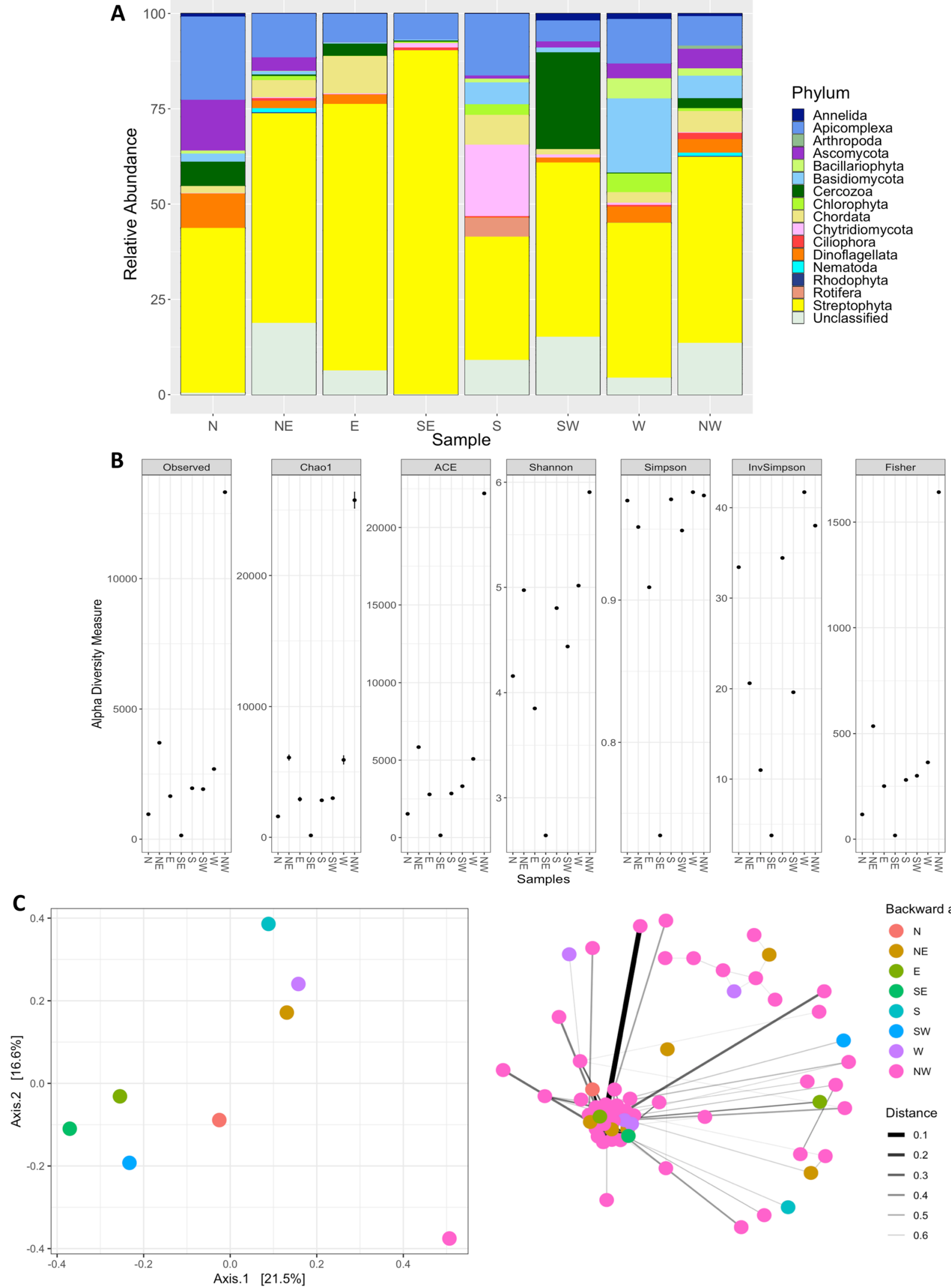

Backward air trajectory

$\mathrm{N}$

NE

E

SE

$S$

sw

W

NW

Distance

- 0.2

$-0.4$

$-0.5$

0.6 
4Fig.3 Comparison of eukaryotic populations at phylum level in eight backward air trajectories in the Red Sea region. a Taxonomic composition of eukaryotic reads at the phylum level. b Alpha diversity measurements of eukaryotic communities per backward air trajectory. Each panel represents one alpha diversity measure as follow: observed=total number of SVs observed; Chaol and ACE=richness estimators (estimate the total number of SVs present in a community); Shannon, Simpson and InvSimpson=microbial indexes of diversity; Fisher=parametric index of diversity that models taxa as logseries distribution. $\mathbf{c}$ Beta diversity as Principal coordinates analysis (PCoA) derived from Bray-Curtis distances among samples of the eight populations. The closer the samples in the graph, the higher their similarity. Each data point represents sample type, and different colors represent different backward air trajectory. In the same panel, a network that represents distance relationships between phyla among backward air trajectories based on similarity of co-occurrence relationships inferred from bray distance matrix. Thicker lines representing stronger correlations. Each data point represents an individual sample, and different colors represent different backward air trajectories

air masses sampled from different trajectories was rather conserved among air masses. The most frequently detected taxa were Streptophyta in the samples that came from SE and E, Apicomplexa in N, NE, and S backward trajectories, Ascomycota in the $\mathrm{N}$ samples, Basidiomycota in the $\mathrm{W}$ atmospheric source, Chordata in the S, E, and NW backward trajectory, Chytridiomycota in S origins, Annelida in SW and $\mathrm{W}$ air sources, Bacillariophyta in N, W, and NW airborne dust samples, Chlorophyta in $\mathrm{W}$ and $\mathrm{S}$ air sources, and Arthropoda and Nematoda in NE and NW samples (Fig. 3a, S2C).

No significant clustering (ANOVA, $p<0.83$ ) of AEC SVs between different backward air mass trajectories (Fig. 3c, S3C) based on NMDS and PCoA of Bray-Curtis distances among samples. The history of the atmospheric air transportation has no significant effect on the AEC diversity and richness (Fig. 3b, ANOVA, $p=0.76$ ).

The relationship between dust load and AEC diversity indexes was tested using linear regression analysis (Fig. 4). There was no relationship between dust concentration and the AEC diversity and richness $\left(R^{2}=0.014,0.001, p=0.18\right.$ and 0.67 , for Shannon and Chao1 index, respectively).

Characterization of atmospheric eukaryotic communities in the Red Sea region provide a representation of the taxa in the air and their relative abundance in regard to sampling domain, dust origins, and sampling seasons. The most abundant micro and macro eukaryotes in the Red Sea atmosphere are similar to those reported elsewhere, such as those typically reported in the atmosphere of Spain (Caliz et al. 2018), China (Liu et al. 2019), Japan (Tanaka et al. 2019) and Brazil (Womack et al. 2015), which may be due to the influence of marine and terrestrial environments as point sources for aerosolized micro and macro eukaryotes to the atmosphere.

In general, the AEC over the Red Sea was dominated by Streptophyta (Liliopsida (Poaceae)), a plants clade that release large amounts of pollen into the atmosphere transporting from arid terrestrial habitats (Bouchenak-Khelladi et al. 2014) that might cause allergic respiratory disease
(García-Mozo 2017) in different regions and seasons based on changes in land uses and climate (García-Mozo et al. 2016). Streptophyta bioaerosols were mostly transported to the Red Sea region from the Arabian Peninsula in all seasons. However, Streptophyta was not in detectable quantity in the Red Sea surface water. Dust particles in the global dust belt originate from arid regions, and is, therefore, expected to contain significant loads of arid plant material, as demonstrated here for dust over the Red Sea, receiving inputs from the Sahara Desert and deserts in the Arabian Peninsula.

The interaction between surface waters and airborne dust in the Red Sea (Parajuli et al. 2020) could be the main reason for Dinophyceae being aerosolized into the atmosphere since this group dominates the phytoplankton community in the Red Sea (Touliabah et al. 2010). In addition, the aerosolized biological materials of Annelida (Polychaeta) over the Red Sea might also result from air-sea interactions (Reuscher 2016).

In the atmospheric dust, the high number of SVs belonging to Apicomplexa (Conoidasida), a parasitic alveolate that infects all mammals, some birds, some fish, some reptiles, and some amphibians in their gastrointestinal tract, might be of concern in regard to human and animal health exposed to these air masses (Oborník 2020). The Apicomplexa group has been recently reported in suspended dust in airplane cabins (Sun et al. 2020) and reported in the southeast Mediterranean atmosphere (Katra et al. 2014). Ascomycota (Sordariomycetes and Saccharomycetes) are large classes comprise some plant and mammalian pathogens and many members with a role in nutrient cycling (Llopis et al. 2014; Li et al. 2016). They are found in terrestrial, freshwater and marine habitats globally (Oborník 2020) and commonly identified in indoor and outdoor atmospheres (Adams et al. 2013). Transported mostly from the west, Basidiomycota (Malasseziomycetes and Tremellomycetes) consists of commensal and pathogenic organisms and spores that are associated with allergies in humans (Moelling and Broecker 2020). This fungal phylum is associated with humid ecosystems and releases the spores in the night when atmospheric humidity is relatively high (Elbert et al. 2007; Gusareva et al. 2019). Hence, the entire globe and especially the Red Sea atmosphere, characterized by high humidity, would be a suitable environment for Basidiomycota, particularly as atmospheric humidity increases as a result of the global warming (Raymond et al. 2020).

A number of Chordata-related SVs identified in the airborne dust represented by Primates, Cetacea and Aves, while represented by Appendicularia in the Red Sea surface water. Identifying aerosolized biological materials from Primates, Cetacea and Aves support the fact that micro-sized tissue fragments and debris originating from 
Fig. 4 The correlations between alpha diversity measure Chao 1 and Shannon and the dust concentrations along the sampling period of AEC. Each data point represents an individual sample. The blue line represents the regression line and the blue band around it represents the 95\% confidence for the regression line

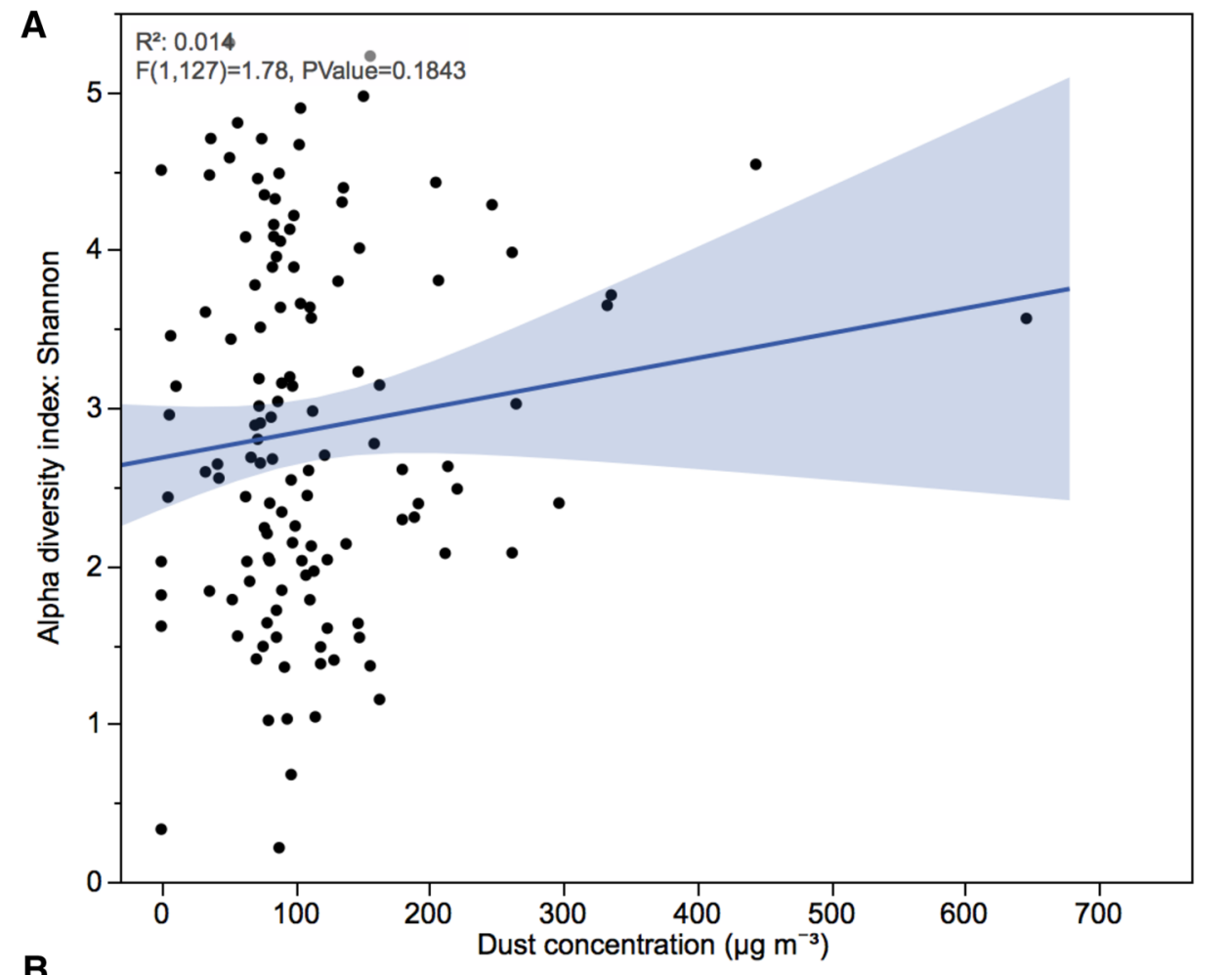

B

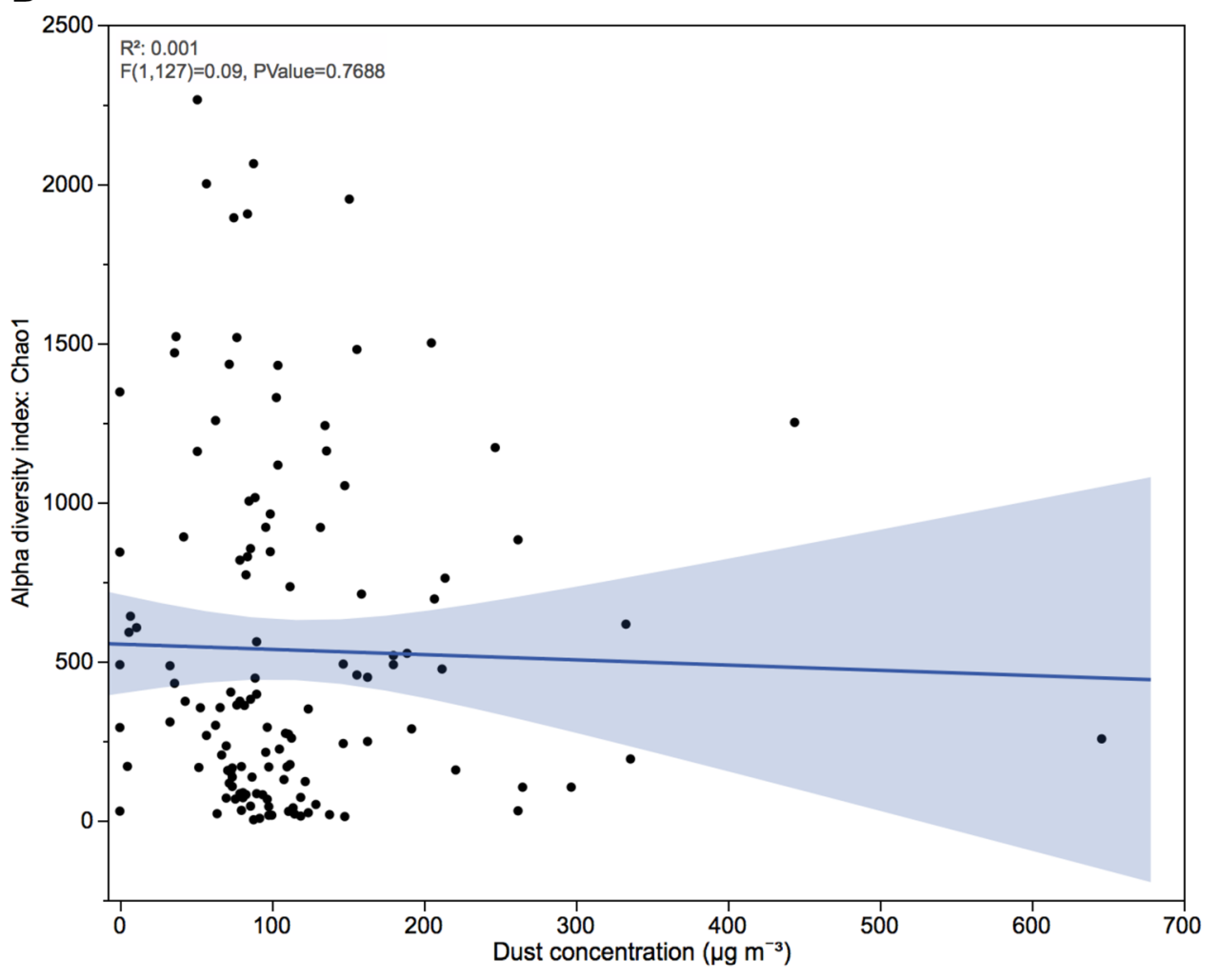

humans and animals could be airborne and transported through the atmospheric (Després et al. 2012). Detection of Appendicularia SVs is expected, as it is one of the most abundant zooplankton in the upper layers of the Red Sea water (Rasul and Stewart 2019).
Remarkably, a high number of eukaryotic SVs were unique to the onshore air samples compared to offshore air and surface water, which suggests a combination of both soil and marine-derived micro and macro eukaryotes. While AEC diversity is significantly differed per sample location 
and type (onshore air, offshore air, and surface water), the three sample types share similar phylotypes as a consequence of air-sea exchange processes (Mayol et al. 2014; Tesson et al. 2016). However, the higher diversity of terrestrial eukaryotes in air samples which can be transported over long distances (Mayol et al. 2017), indicates that some species have spores adapted to the harsh conditions characteristic of the airborne habitat (Aalismail et al. 2019).

A recent study reported that AEC is influenced more by environmental conditions compared to airborne prokaryote communities (Tanaka et al. 2019). Hence, the airborne eukaryotic richness and diversity in the Red Sea region also showed variability over seasonal conditions, consistent with the eukaryotes in the Red Sea (Pearman et al. 2017). The AEC was most diverse in spring, due to the increased loads resulting from pollen released by flowering plants (RuizValenzuela and Aguilera 2018), as the AEC is dominated by plant-related DNA. However, the independence of diversity and richness of the origin of the air masses sampled and dust concentrations may relate to the suspension period of AEC in the global dust belt, as eukaryotic cells can be suspended and transported freely through the atmosphere without attachment to dust particles.

\section{Conclusion}

In summary, our results show a diverse Airborne Eukaryotic Community (AEC) in the atmosphere over the Red Sea. High percentages of terrestrially derived micro and macro eukaryotes are detected in the air, showing a significant transport of soil, plant, and animal-related unicellular eukaryotes, especially, during the spring flowering seasons, in addition, the free DNA or cell debris of several eukaryotes are emitted from the upper layers of the Red Sea water to the atmosphere. The study outcomes indicate the presence of human, plant, and animal pathogens in the air over the Red Sea, pointing at a role of atmospheric transport as a vector potentially transporting human pathogens across large distances, while large-scale transport of pollen may play an important role in the genetic connectivity of arid plants present across the Global Dust Belt. Eukaryotes eDNA in the air from seawater may also be transported and exchanged across water bodies that are partially, Arabian Gulf and the Mediterranean Sea, or entirely, the Red Sea, overlaid by the Global Dust Belt.

Supplementary Information The online version contains supplementary material available at https://doi.org/10.1007/s41748-021-00219-4.

Acknowledgements We thank Ms. Razan Yahya, Dr. Jesus Arrieta, the technicians of CMOR, and the crew of R/V Thuwal for help during sampling. We also thank Ms. Wajitha J. Raja Mohamed Sait for her assistance in DNA extraction and Dr. Chakkiat Antony for his help in the data submission.

Author contributions CMD and NAA initiated this study; NAA and RDR designed and tested the extraction approach and extracted and prepared the samples for sequencing; MC collected the samples; NAA and NG performed the data analyses. CMD and NAA wrote the manuscript and all authors contributed to improving the manuscript. All authors read and approved the final manuscript.

Funding This research was supported by funding supplied by King Abdullah University of Science and Technology through base-line funding to CMD.

Data availability All sequence data generated by this study have been submitted to the ENA (European Nucleotide Archive) under the accession number PRJEB43916.

\section{Declarations}

Conflict of interest The authors declare no competing interests.

Open Access This article is licensed under a Creative Commons Attribution 4.0 International License, which permits use, sharing, adaptation, distribution and reproduction in any medium or format, as long as you give appropriate credit to the original author(s) and the source, provide a link to the Creative Commons licence, and indicate if changes were made. The images or other third party material in this article are included in the article's Creative Commons licence, unless indicated otherwise in a credit line to the material. If material is not included in the article's Creative Commons licence and your intended use is not permitted by statutory regulation or exceeds the permitted use, you will need to obtain permission directly from the copyright holder. To view a copy of this licence, visit http://creativecommons.org/licenses/by/4.0/.

\section{References}

Aalismail NA, Ngugi DK, Diaz-Rua R, Alam I, Cusack M, Duarte CM (2019) Functional metagenomic analysis of dust-associated microbiomes above the Red Sea. Sci Rep 9:13741

Aalismail NA, Díaz-Rúa R, Ngugi DK, Cusack M, Duarte CM (2020) Aeolian prokaryotic communities of the global dust belt over the Red Sea. Front Microbiol 11:538476

Adams RI, Miletto M, Taylor JW, Bruns TD (2013) Dispersal in microbes: fungi in indoor air are dominated by outdoor air and show dispersal limitation at short distances. ISME J 7:1262-1273

Rasul NMA, Stewart ICF (2019) Oceanographic and biological aspects of the Red Sea. In: Springer oceanography, 1st edn. Springer International Publishing, Cham

Bianco A, Passananti M (2020) Atmospheric micro and nanoplastics: an enormous microscopic problem. Sustainability 12:7327

Bouchenak-Khelladi Y, Muasya AM, Linder HP (2014) A revised evolutionary history of Poales: origins and diversification. Bot J Linn Soc 175:4-16

Bower AS, Farrar JT (2015) Air-Sea interaction and horizontal circulation in the Red Sea. In: Rasul NMA, Stewart ICF (eds) The Red Sea: the formation, morphology, oceanography and environment of a young ocean basin. Springer, Berlin, Heidelberg, pp 329-342

Bürgmann H, Pesaro M, Widmer F, Zeyer J (2001) A strategy for optimizing quality and quantity of DNA extracted from soil. J Microbiol Methods 45:7-20 
Caliz J, Triado-Margarit X, Camarero L, Casamayor EO (2018) A long-term survey unveils strong seasonal patterns in the airborne microbiome coupled to general and regional atmospheric circulations. Proc Natl Acad Sci USA 115:12229-12234

Callahan BJ, Sankaran K, Fukuyama JA, Mcmurdie PJ, Holmes SP (2016) Bioconductor workflow for microbiome data analysis: from raw reads to community analyses. F1000Res 5:1492

Cho BC, Hwang CY (2011) Prokaryotic abundance and 16S rRNA gene sequences detected in marine aerosols on the East Sea (Korea). FEMS Microbiol Ecol 76:327-341

Clare EL, Economou CK, Faulkes CG, Gilbert JD, Bennett F, Drinkwater R, Littlefair JE (2021) eDNAir: proof of concept that animal DNA can be collected from air sampling. PeerJ 9:e11030

Després V, Huffman JA, Burrows SM, Hoose C, Safatov A, Buryak G, Fröhlich-Nowoisky J, Elbert W, Andreae M, Pöschl U, Jaenicke R (2012) Primary biological aerosol particles in the atmosphere: a review. Tellus B Chem Phys Meteorol 64:15598

Eladawy A, Nadaoka K, Negm A, Abdel-Fattah S, Hanafy M, Shaltout M (2017) Characterization of the northern Red Sea's oceanic features with remote sensing data and outputs from a global circulation model. Oceanologia 59:213-237

Elbert W, Taylor PE, Andreae MO, Pöschl U (2007) Contribution of fungi to primary biogenic aerosols in the atmosphere: wet and dry discharged spores, carbohydrates, and inorganic ions. Atmos Chem Phys 7:4569-4588

Fröhlich-Nowoisky J, Kampf CJ, Weber B, Huffman JA, Pöhlker C, Andreae MO, Lang-Yona N, Burrows SM, Gunthe SS, Elbert W, Su H, Hoor P, Thines E, Hoffmann T, Després VR, Pöschl U (2016) Bioaerosols in the Earth system: climate, health, and ecosystem interactions. Atmos Res 182:346-376

García-Mozo H (2017) Poaceae pollen as the leading aeroallergen worldwide: a review. Allergy 72:1849-1858

García-Mozo H, Oteros JA, Galán C (2016) Impact of land cover changes and climate on the main airborne pollen types in Southern Spain. Sci Total Environ 548-549:221-228

Genitsaris S, Kormas KA, Christaki U, Monchy S, Moustaka-Gouni M (2014) Molecular diversity reveals previously undetected airdispersed protist colonists in a Mediterranean area. Sci Total Environ 478:70-79

Genitsaris S, Stefanidou N, Katsiapi M, Kormas KA, Sommer U, Moustaka-Gouni M (2017) Variability of airborne bacteria in an urban Mediterranean area (Thessaloniki, Greece). Atmos Environ 157:101-110

Griffin DW (2007) Atmospheric movement of microorganisms in clouds of desert dust and implications for human health. Clin Microbiol Rev 20(3):459-477

Gusareva ES, Acerbi E, Lau KJX, Luhung I, Premkrishnan BNV, Kolundžija S, Purbojati RW, Wong A, Houghton JNI, Miller D, Gaultier NE, Heinle CE, Clare ME, Vettath VK, Kee C, Lim SBY, Chénard C, Phung WJ, Kushwaha KK, Nee AP, Putra A, Panicker D, Yanqing K, Hwee YZ, Lohar SR, Kuwata M, Kim HL, Yang L, Uchida A, Drautz-Moses DI, Junqueira ACM, Schuster SC (2019) Microbial communities in the tropical air ecosystem follow a precise diel cycle. Proc Natl Acad Sci 116:23299-23308

Ipcc (2013) Climate Change 2013: the physical science basis. Contribution of working group I to the fifth assessment report of the Intergovernmental Panel on Climate Change. Cambridge University Press, Cambridge

Katra I, Arotsker L, Krasnov H, Zaritsky A, Kushmaro A, Ben-Dov E (2014) Richness and diversity in dust stormborne biomes at the Southeast Mediterranean. Sci Rep 4:5265

Kotz S, Read CB, Balakrishnan N, Vidakovic B, Johnson NL (2004) Encyclopedia of statistical sciences

Lan Y, Wang Q, Cole JR, Rosen GL (2012) Using the RDP classifier to predict taxonomic novelty and reduce the search space for finding novel organisms. PLOS ONE 7:e32491
Li M, Qi J, Zhang H, Huang S, Li L, Gao D (2011) Concentration and size distribution of bioaerosols in an outdoor environment in the Qingdao coastal region. Sci Total Environ 409:3812-3819

Li GJ, Hyde KD, Zhao RL, Hongsanan S, Abdel-Aziz FA, AbdelWahab MA, Alvarado P, Alves-Silva G, Ammirati JF, Ariyawansa HA, Baghela A, Bahkali AH, Beug M, Bhat DJ, Bojantchev D, Boonpratuang T, Bulgakov TS, Camporesi E, Boro MC, Ceska O, Chakraborty D, Chen JJ, Chethana KWT, Chomnunti P, Consiglio G, Cui BK, Dai DQ, Dai YC, Daranagama DA, Das K, Dayarathne MC, De Crop E, De Oliveira RJV, De Souza CAF, De Souza JI, Dentinger BTM, Dissanayake AJ, Doilom M, Drechsler-Santos ER, GhobadNejhad M, Gilmore SP, Góes-Neto A, Gorczak M, Haitjema CH, Hapuarachchi KK, Hashimoto A, He MQ, Henske JK, Hirayama K, Iribarren MJ, Jayasiri SC, Jayawardena RS, Jeon SJ, Jerônimo GH, Jesus AL, Jones EBG, Kang JC, Karunarathna SC, Kirk PM, Konta S, Kuhnert E, Langer E, Lee HS, Lee HB, Li WJ, Li XH, Liimatainen K, Lima DX, Lin CG, Liu JK, Liu XZ, Liu ZY, Luangsa-Ard JJ, Lücking R, Lumbsch HT, Lumyong S, Leaño EM, Marano AV, Matsumura M, Mckenzie EHC, Mongkolsamrit S, Mortimer PE, Nguyen TTT, Niskanen T, Norphanphoun C, O'malley MA, Parnmen S, Pawłowska J, Perera RH, Phookamsak R, Phukhamsakda C, Pires-Zottarelli CLA, Raspé O, Reck MA, Rocha SCO, De Santiago ALCMA, Senanayake IC, Setti L, Shang QJ, Singh SK et al (2016) Fungal diversity notes 253-366: taxonomic and phylogenetic contributions to fungal taxa. Fungal Divers 78:1-237

Liu H, Hu Z, Zhou M, Hu J, Yao X, Zhang H, Li Z, Lou L, Xi C, Qian H, Li C, Xu X, Zheng P, Hu B (2019) The distribution variance of airborne microorganisms in urban and rural environments. Environ Pollut 247:898-906

Llopis S, Hernández-Haro C, Monteoliva L, Querol A, Molina M, Fernández-Espinar MT (2014) Pathogenic potential of Saccharomyces strains isolated from dietary supplements. PloS one 9(5):e98094

Martin M (2011) Cutadapt removes adapter sequences from highthroughput sequencing reads. EMBnet J 17:3

Mayol E, Jiménez MA, Herndl GJ, Duarte CM, Arrieta JM (2014) Resolving the abundance and air-sea fluxes of airborne microorganisms in the North Atlantic Ocean. Fron Microbiol 5:557

Mayol E, Arrieta JM, Jimenez MA, Martinez-Asensio A, GarciasBonet N, Dachs J, Gonzalez-Gaya B, Royer SJ, Benitez-Barrios VM, Fraile-Nuez E, Duarte CM (2017) Long-range transport of airborne microbes over the global tropical and subtropical ocean. Nat Commun 8:201

Michaud JM, Thompson LR, Kaul D, Espinoza JL, Richter RA, Xu ZZ, Lee C, Pham KM, Beall CM, Malfatti F, Azam F, Knight R, Burkart MD, Dupont CL, Prather KA (2018) Taxon-specific aerosolization of bacteria and viruses in an experimental oceanatmosphere mesocosm. Nat Commun 9:2017

Moelling K, Broecker F (2020) Air microbiome and pollution: composition and potential effects on human health, including SARS coronavirus infection. J Environ Public Health 2020:1-14

Oborník M (2020) Photoparasitism as an intermediate state in the evolution of apicomplexan parasites. Trends Parasitol 36:727-734

Parajuli SP, Stenchikov GL, Ukhov A, Shevchenko I, Dubovik O, Lopatin A (2020) Aerosol vertical distribution and interactions with land/sea breezes over the eastern coast of the Red Sea from lidar data and high-resolution WRF-Chem simulations. Atmos Chem Phys 20:16089-16116

Pearman JK, Ellis J, Irigoien X, Sarma YVB, Jones BH, Carvalho S (2017) Microbial planktonic communities in the Red Sea: high levels of spatial and temporal variability shaped by nutrient availability and turbulence. Sci Rep 7:6611 
Prakash PJ, Stenchikov G, Kalenderski S, Osipov S, Bangalath H (2015) The impact of dust storms on the Arabian Peninsula and the Red Sea. Atmos Chem Phys 15:199-222

Prospero JM, Ginoux P, Torres O, Nicholson SE, Gill TE (2002) Environmental characterization of global sources of atmospheric soil dust identified with the Nimbus 7 total ozone mapping spectrometer (TOMS) absorbing aerosol producT. Rev Geophys 40:1-31

Rahav E, Paytan A, Chien C-T, Ovadia G, Katz T, Herut B (2016) The impact of atmospheric dry deposition associated microbes on the Southeastern Mediterranean Sea surface water following an intense dust storm. Front Mar Sci 3:127

Raymond C, Matthews T, Horton RM (2020) The emergence of heat and humidity too severe for human tolerance. Sci Adv 6:eaaw1838

Reuscher MG (2016) Ampharetidae (Annelida: Polychaeta) from the Red Sea reef Al Fahal (Saudi Arabia) with the description of a new species. J Mar Biol Assoc UK 97:99-104

Ruiz-Valenzuela L, Aguilera F (2018) Trends in airborne pollen and pollen-season-related features of anemophilous species in Jaen (south Spain): a 23-year perspective. Atmos Environ 180:234-243

Stein AF, Draxler RR, Rolph GD, Stunder BJB, Cohen MD, Ngan F (2015) Noaa's hysplit atmospheric transport and dispersion modeling system. Bull Am Meteorol Soc 96:2059-2077

Stoeck T, Bass D, Nebel M, Christen R, Jones MD, Breiner HW, Richards TA (2010) Multiple marker parallel tag environmental DNA sequencing reveals a highly complex eukaryotic community in marine anoxic water. Mol Ecol 19(Suppl 1):21-31

Sun Y, Fu X, Li Y, Yuan Q, Ou Z, Lindgren T, Deng Y, Norbäck D (2020) Shotgun metagenomics of dust microbiome from flight deck and cabin in civil aviation aircraft. Indoor Air 30:1199-1212

Tanaka D, Sato K, Goto M, Fujiyoshi S, Maruyama F, Takato S, Shimada T, Sakatoku A, Aoki K, Nakamura S (2019) Airborne microbial communities at high-altitude and suburban sites in Toyama, Japan suggest a new perspective for bioprospecting. Front Bioeng Biotechnol 7:12

Tesson SVM, Skjøth CA, Šantl-Temkiv T, Löndahl J, Voordouw G (2016) Airborne microalgae: insights, opportunities, and challenges. Appl Environ Microbiol 82:1978-1991
Touliabah H, El-Kheir WS, Kuchari MG, Abdulwassi NH (2010) Phytoplankton composition at Jeddah Coast—Red Sea Saudi Arabia in relation to some ecological factors. JKAU Sci 22:115-131

Tovar-Sãnchez A, Arrieta JM, Duarte CM, Sañudo-Wilhelmy SA (2014) Spatial gradients in trace metal concentrations in the surface microlayer of the Mediterranean Sea. Front Mar Sci 1:79

Vila-Costa M, Barberan A, Auguet J-C, Sharma S, Moran MA, Casamayor EO (2013) Bacterial and archaeal community structure in the surface microlayer of high mountain lakes examined under two atmospheric aerosol loading scenarios. FEMS Microbiol Ecol 84:387-397

Wickham H (2016) ggplot2: Elegant graphics for data analysis. Springer, New York. ISBN 978-3-319-24277-4, https://ggplot2. tidyverse.org

Wilkinson SP, Davy SK, Bunce M, Stat M (2018) Taxonomic identification of environmental DNA with informatic sequence classification trees. PeerJ 6:e26812v1

Wiśniewska K, Lewandowska AU, Śliwińska-Wilczewska S (2019) The importance of cyanobacteria and microalgae present in aerosols to human health and the environment-review study. Environ Int 131:104964

Womack AM, Artaxo PE, Ishida FY, Mueller RC, Saleska SR, Wiedemann KT, Bohannan BJM, Green JL (2015) Characterization of active and total fungal communities in the atmosphere over the Amazon rainforest. Biogeosciences 12:6337-6349

Woo AC, Brar MS, Chan Y, Lau MCY, Leung FCC, Scott JA, Vrijmoed LLP, Zawar-Reza P, Pointing SB (2013) Temporal variation in airborne microbial populations and microbially-derived allergens in a tropical urban landscape. Atmos Environ 74:291-300

Yahya RZ, Arrieta JM, Cusack M, Duarte CM (2019) Airborne prokaryote and virus abundance over the Red Sea. Front Microbiol 10:1112

Yamaguchi N, Ichijo T, Sakotani A, Baba T, Nasu M (2012) Global dispersion of bacterial cells on Asian dust. Sci Rep 2:525 